\title{
Comparison of DC-DC Converter Topologies for Electric Vehicular Application
}

\author{
${ }^{* 1}$ Manisha Gaikwad, ${ }^{2}$ Manjusha Palandurkar \\ ${ }^{1,2}$ Shri Ramdeobaba College of Engineering and Management, Nagpur, India. \\ Email: '1gaikwadmb@rknec.edu, ${ }^{2}$ palandurkarmv@rknec.edu
}

Received: 06th October 2019, Accepted: 20th November 2019, Published: 31st December 2019

\begin{abstract}
In this paper comparison of various topologies of dc-dc converter for electric vehicular application are presented. Non-isolated converter is the first one and the second one is isolated dc-dc converter. Non-isolated dc-dc converter have low cost and simple, but there is one drawback in it that input and output are not isolated each other. To overcome this drawback, an isolated dc-dc converter is used. An isolated dc-dc converter consist of transformer, which is used to step-down and step-up the voltage as well as it isolate the input and output. To trigger the converter switches, Sinusoidal-Pulse-Width- modulation technique is preferred. Comparison of proposed model of various dcdc converter are simulated in MATLAB Simulink. The simulation results helps to select the best converter for electric vehicle.
\end{abstract}

Keywords

Li-ion Battery, DC-DC Converter, SiC MOSFET, Transformer, DC Motor.

\section{Introduction}

The electrification of the transportation has importantly augmented in past ten years. This is mainly to drop down the utilization of greenhouse emissions and fossil fuels. Battery operated vehicles are deliberately giving place of the vehicle based on internal combustion engine as one of the key for future transport, which offers better petroleum economy and lower emissions. Though, the increasing exploitation of these vehicles could have a great impact on the grid. Lately, the contamination problems with fast populace growth are turn out to be world problems. Due to the least amount of air contamination and small or zero greenhouse gas emissions, hybrid electric vehicle (HEV) and electric vehicle (EV) technology is growing interest as an alternate solution in most of the countries around the world. Cars and trucks are liable to produce $25 \%$ of $\mathrm{CO} 2$ emission and other transportation methods account for another $12 \%$ of $\mathrm{CO} 2$ emission. Electric trucks and electric cars are often cleaner than the engine operated vehicles. Thus a number of developments conceded to turn down of electric vehicles. Electric vehicles are different from fossil fuel power-driven vehicles. In electric vehicles power is consumed, which is generated from sources like including nuclear power, fossil fuels and renewable sources such as wind power, solar power and tidal power. The extensive adoption of the electric vehicle fetch considerable changes for society in terms of technologies which we utilize for own transportation. It also does our economies away from fuel [1]-[4].

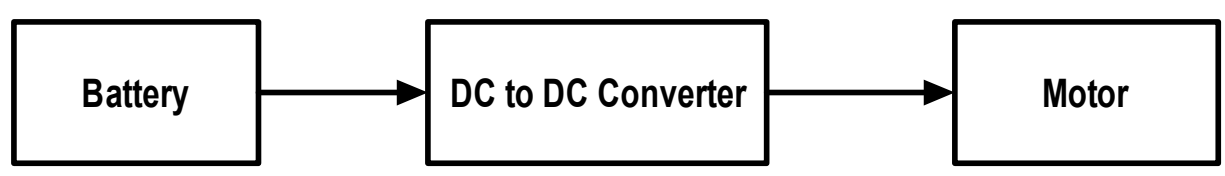

Figure 1: Block Diagram of an Electric Vehicle Power Train.

The block diagram of electric vehicle power train is shown in Figure 1. This paper is prepared as follows: In Section 1, the introduction of electric vehicle is discussed. Section 2 described the different proposed replica of the whole system. Simulation results of isolated dc- dc converter and non-isolated converter i.e boost converter, buck converter and buckboost converter are shown in section 3. Conclusion and future scope are given in section 4 .

\section{Electric Vehicle}

In electric vehicles (EVs) at the place where they are operated has no exhaust tube air pollutant. They also normally less noise production than an internal ignition engine vehicle, whether atin running condition or in rest. EVs dispense silent and downy operation thus have less noise and trembling than internal ignition engines. In EV cars previously used Nickel Metal Hydride batteries. These types of battery are considered obsolete due to their self-discharge tendency in the heat. Therefore now a day's lithium- ion batteries are the most popular battery for EVs. Lithium ion batteries have long life, higher power density and higher energy density than most other empirical batteries. EVs have minor direct emissions, each and every one rely on electrical energy produced through electrical power generation system and will generally effuse contamination and produce waste material, unless energy is generated by non- conventional power plants. EVs utilize electrical energy from electrical utility/grid operator. By some modification in the electrical power plants, EVs can be more capable, a lesser amount of pollution and less costly to run. In general, the electric vehicle is energy competent, cleaner and environment friendly than the vehicle which is depend on fossil fuels [5]-[8]. 


\section{Description of Proposed Model}

One of the type of power converter in electrical engineering is the DC to DC converter. It converts dc power from one voltage to another voltage. It delivers the electrical energy to the output at different voltage level just by storing the input energy momentarily. Storing of energy is done by the component of electric field (capacitors) or by the component of magnetic field (inductors, transformers). To transfer power from the input to the output in only one direction, DC-DC converters can be constructed. Still, entire topologies of DC-DC converter can be built of bidirectional converter. To transfer power in either direction, a bi-directional converter can be used. It is helpful in regenerative braking applications. There are two types of $\mathrm{dc}-\mathrm{dc}$ converter are discussed in this paper, non-isolated converter and isolated converter.

(i)Non- Isolated Converter:- As there is no issue of dielectric isolation between input and output and to stepped up and stepped down by a moderately small ratio, a non-isolated converter is generally used. In this paper boost converter, buck converter and buck-boost types of non-isolated converters are discussed. For step-down voltage and step-up voltage, the buck converter and the boost converter are used respectively. To step-up or step-down the voltage, the buck-boost type converters are used.

\section{A. Buck Converter:}

To step down the voltage, buck converter is generally used. The basic topology of buck converter is shown in figure 2 . Buck converter takes a higher voltage and its output will be lesser than the input voltage., Switch $\mathrm{S}_{1}$ is close at $t=0$ in mode 1. The current flows from input to output through switch, filter inductor $L$, filter capacitor $C$. Switch $\mathrm{S}_{1}$ is open at $t$ $=t_{1}$ in mode 2 . The diode $D \mathrm{~m}$ will conducts due to stored energy of the inductor, and current flows in the inductor through inductor, capacitor, diode $D_{\mathrm{m}}$ and load [9].

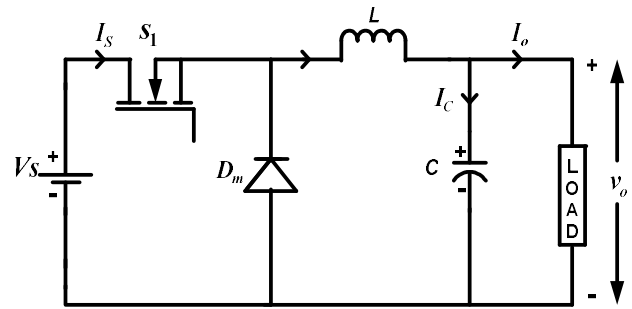

Figure 2: Buck Converter

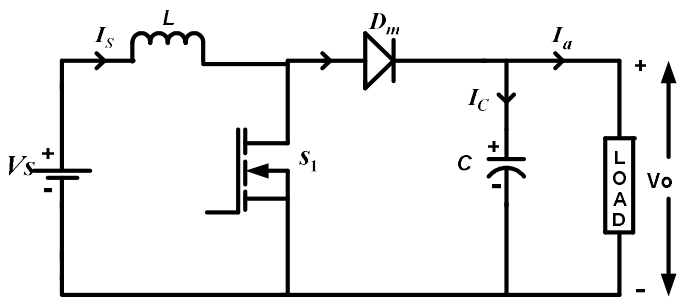

Figure 3: Boost Converter

\section{B. Boost Converter}

Boost converter takes the input voltage and boost that voltage at the output side. Figure 3 shows the basic topology of boost converter using a power MOSFET. Switch $\mathrm{S}_{1}$ is switched on at $t=0$ in mode 1.The input current rises flows through inductor $L$ and $\mathrm{s}$ witch $\mathrm{S}_{1}$. Switch $\mathrm{S}_{1}$ is switched off at $t=t_{1}$ in mode 2 . In mode 2, the current that was flowing through the switch would now flow through inductor $L$, capacitor $C$, load and diode $D$ m. The inductor current decreases as far as switch $\mathrm{S}_{1}$ is turned on again in the next cycle and the energy stored in inductor $L$ is transferred to the load [9].

\section{Buck-Boost Converter}

Buck-Boost Converter is shown in figure 4. To decrease and increase the voltage level relative to the input voltage, buck-boost converter is used. The operation of this converter are split into two modes. When switch $\mathrm{S}_{1}$ is closed during mode 1, diode $D_{\mathrm{m}}$ is reversed biased. The input current flows through switch and inductor. By opening the switch $\mathrm{S}_{1}$ in mode 2 and the current in inductor would flows through inductor $L$, diode $D \mathrm{~m}$, capacitor $C$, and the load. Inductor $L$ delivers its energy to the load and the current flows through inductor would drop till switch $\mathrm{S}_{1}$ is closed anew in the next half cycle. [9].

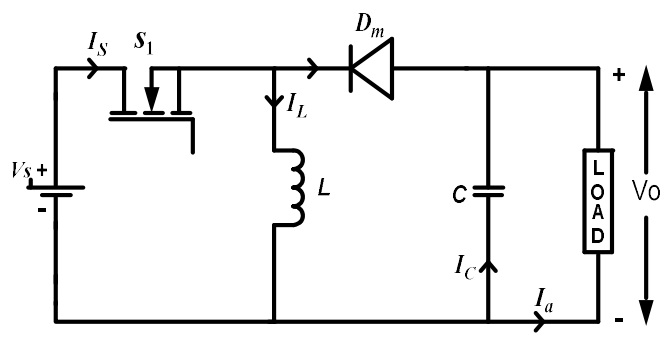

Figure 4: Buck-Boost Converter.

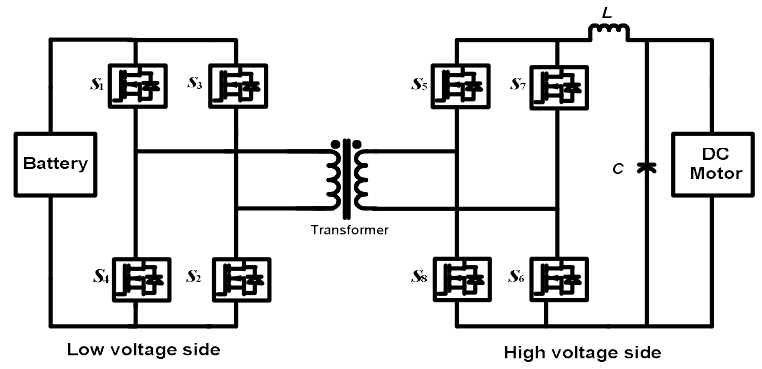

Figure 5: Isolated DC-DC Converter 
(ii)Isolated DC-DC Converter:-.

For the application of electric vehicles where isolation is required between input and output, isolated dc-dc converter are also used. It is shown in figure 5. Various types of converter comes under this group, for example push-pull, full bridge etc. By making some modification in these converters, bi-directional converter (reversal of power) can be possible.

In isolated converter, two converters are used. One is full-bridge rectifier and other is full-bridge inverter are the parts of isolated dc-dc converter. An ac output is amalgamate from a dc input by switching on and off the switches in an proper order. To convert dc input voltage into ac output voltage at suitable magnitude, full bridge inverter is used. In medium and low power applications inverter gives quasi-square or square wave value of output which is tolerable but sinusoidal waveform is requisite in high-power applications.

To convert ac output voltage of transformer into dc voltage, full-bridge rectifier is used which is further fed to dc motor.

\section{Methodology}

To get low distortion in sinusoidal output, inverters are designed carefully.[9].There are different techniques to vary the inverter gain. Single- pulse-width modulation(single PWM), Multiple-pulse width modulation(Multiple PWM), Phasedisplacement control and Sinusoidal pulse-width modulation (SPWM) are the commonly used techniques. SPWM control technique has been used in this paper. The SPWM technique produces a sinusoidal waveform by filtering an output pulse waveform with varying width. A high switching frequency leads to a better filtered sinusoidal output waveform. The desired output voltage is achieved by varying the frequency and amplitude of a reference or modulating voltage. The variations in the amplitude and frequency of the reference voltage change the pulse width patterns of the output voltage but keep the sinusoidal modulation. A low-frequency sinusoidal modulating signal is compared with a high frequency triangular signal, which is called the carrier signal. The switching state is changed when the sine waveform intersects the triangular waveform. The crossing positions determine the variable switching times between states.

\section{Non-Isolated Converter}

\section{(a) Buck Converter}
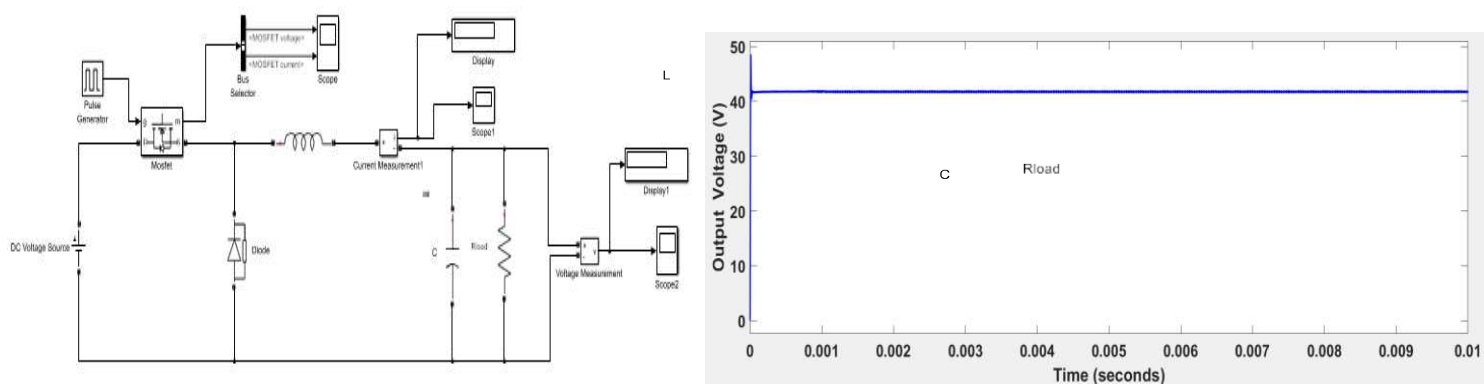

Figure 6(a): Simulation Model of Buck Converter

Figure 6(b): Simulated Result of Buck Converter

(b) Boost Converter

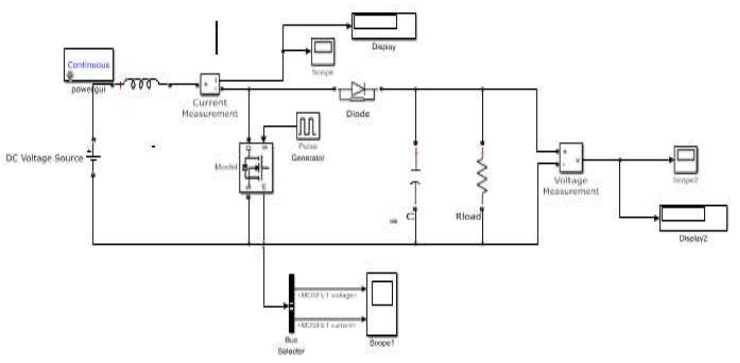

Figure 7(a): Simulation Model of Boost Converter

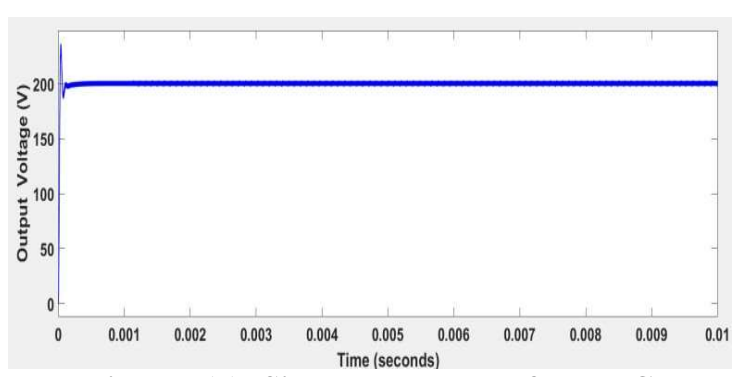

Figure 7(b): Simulated Result of Boost Converter 
(c) Buck- Boost Converter

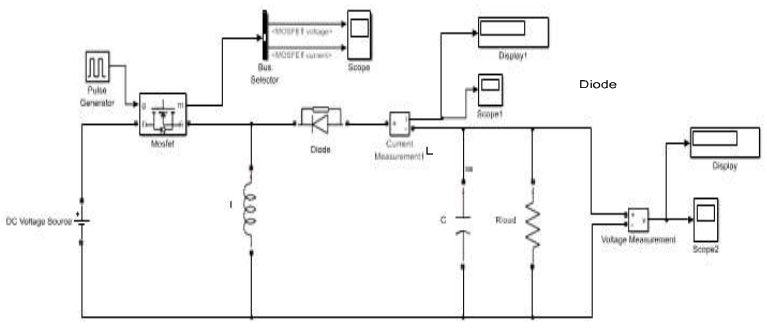

Figure 8(a): Simulation Model of Buck-Boost Converter

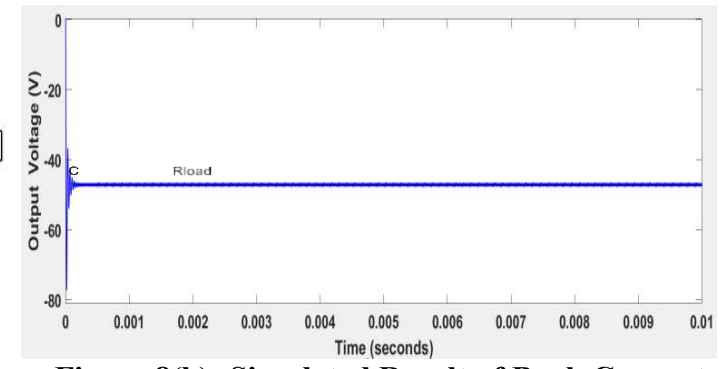

Figure 8(b): Simulated Result of Buck Converter

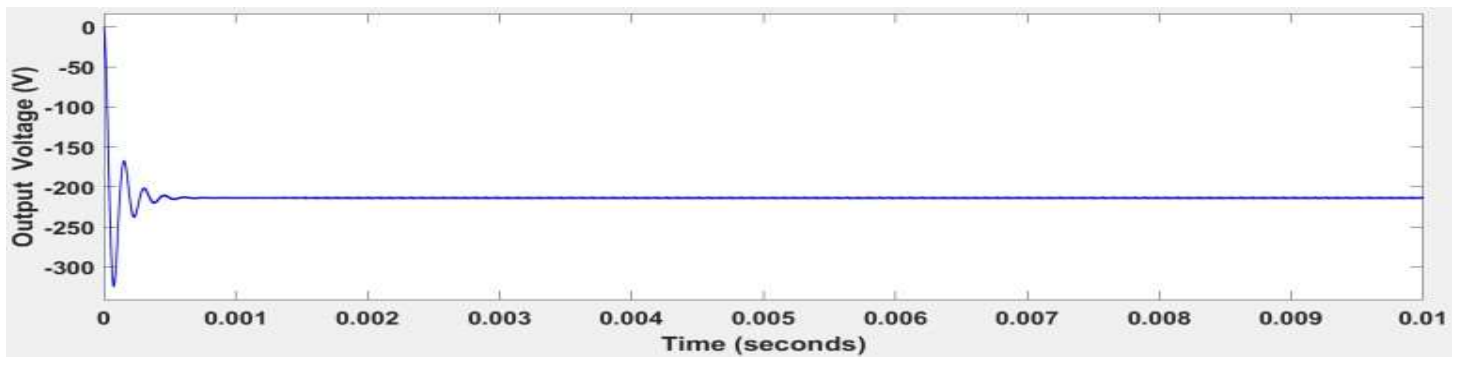

Figure 8(c): Simulated Result of Boost Converter

\section{Isolated DC-DC Converter}

In steady state condition of an isolated dc-dc converter, lithium-ion battery has taken as a source and separately excited DC motor is acting as a load. In Fig. 9(a), DC input is provided by battery to the inverter. Inverter helps to convert this de value of voltage into the ac value of voltage. SPWM technique is used with $\mathbf{0 . 9 5}$ modulation index for triggering the switches. To step-up this voltage level, transformer is used. It also offer segregation between output and input of this type of converter. Conversion of transformer ac output voltage into dc voltage was done by rectifier. To reduce the harmonic contains, C and L filter is constructed and to charge the battery at desired voltage. From figure 9(b) to figure 9(e), the simulated results are shown.

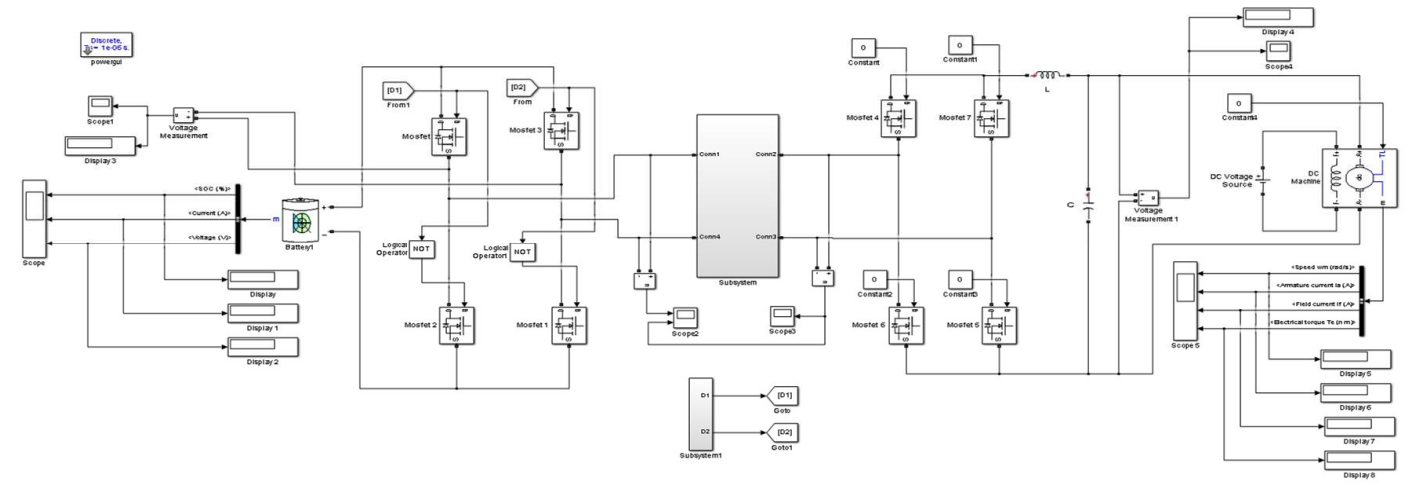

Figure 9(a): Simulation Diagram of Isolated DC-DC Converter

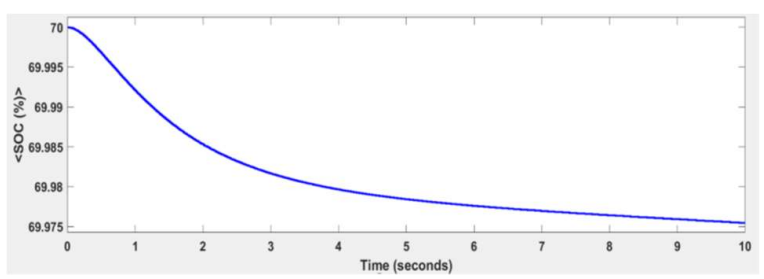

Figure 9 (b): State of Charge of Battery

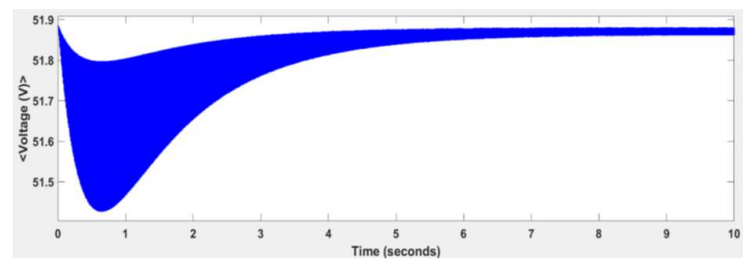

Figure 9(c): Simulated Result of Battery Voltage 


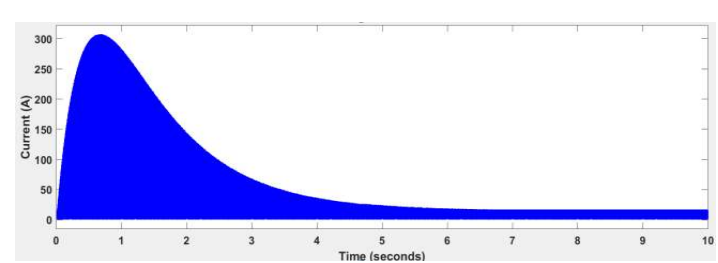

Figure 9(d): Simulated Result of Battery Current

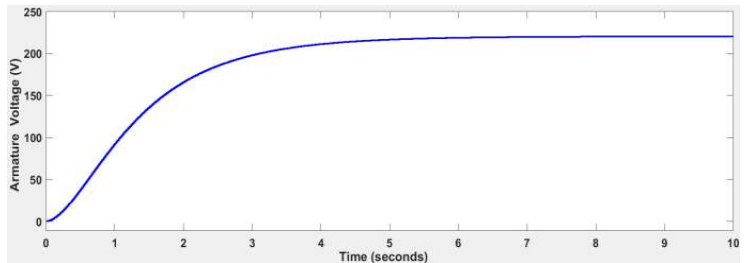

Figure 9(e): Armature Voltage of DC Motor

\begin{tabular}{|l|l|l|l|l|l|}
\hline $\begin{array}{l}\text { Battery } \\
\text { Parameters }\end{array}$ & Values & $\begin{array}{l}\text { Transformer } \\
\text { Parameters }\end{array}$ & Values & $\begin{array}{l}\text { DC Motor } \\
\text { Parameters }\end{array}$ & Values \\
\hline Nominal Voltage & $48 \mathrm{~V}$ & Nominal Power & $1000 \mathrm{VA}$ & Armature Voltage & $221.7 \mathrm{~V}$ \\
\hline Rated Capacity & $500 \mathrm{Ah}$ & $\begin{array}{l}\text { Nominal } \\
\text { Frequency }\end{array}$ & $50 \mathrm{~Hz}$ & Armature Current & $1.823 \mathrm{~A}$ \\
\hline SOC & $69.97 \%$ & Primary Voltage & $51.867 \mathrm{~V}$ & Speed of motor & $2715 \mathrm{rpm}$ \\
\hline $\begin{array}{l}\text { Internal } \\
\text { Resistance }\end{array}$ & $0.00096 \Omega$ & Primary Current & $15.5 \mathrm{~A}$ & Field Current & $0.7509 \mathrm{~A}$ \\
\hline Battery Voltage & $51.862 \mathrm{~V}$ & Secondary Voltage & $368.5 \mathrm{~V}$ & Field Voltage & $120 \mathrm{~V}$ \\
\hline Battery Current & $15 \mathrm{~A}$ & Secondary Current & $2 \mathrm{~A}$ & Electrical torque & $1.41 \mathrm{Nm}$ \\
\hline
\end{tabular}

Table 1: Input and Output Values of Battery, Transformer and DC Motor

\section{Conclusion}

In conclusion, this paper distinguished two dc-dc converter for electric vehicular application. The first converter are a buck, boost, buck/boost non-isolated and the second converter is an isolated. The input and output values of isolated converter (battery, transformer and dc motor) are given in table no. 1. Simulation of non-isolated and isolated dc-dc converter has studied and simulated using MATLAB/Simulink. The non-isolated Buck/Boost converter seems to have lot of merits over the filters size and simple control, the dual active bridge stick out when isolation is necessary between input and output. Analyzing the requisite of the segregation, the Buck/Boost needs an supplementary isolation circuit to assure that it respects the charging and discharging level and standards, while in isolated converter consist of a transformer that acquiesce it to comprehend a propulsive isolation between the input circuit and output circuit and assure the users safety. Future scope of this proposed system is that, bidirectional non-isolated and isolated dc-dc converter can be introduced and performance of this converters can be figure out in MATLAB/Simulink for Battery Fed Electric Vehicle.

\section{References}

[1]Pritam Das, S.Ahmad Mousavi and Gerry Moschopoulos,. "Analysis and design of a non-isolated bidirectional ZVSPWM DC-DC converter with coupled inductors". IEEE Transactions on Power Electronics, pp.2630-2641,2010

[2]Udupi R. Prasanna, Anant Kumar Singh and Kaushik Rajashekara, "Novel bidirectional single- phase single-stage isolated AC-DC converter with PFC for charging of electric vehicles". IEEE Transactions on Transportation Electrification,3(3), pp.536-544, 2017

[3]Lung-Sheng Yang and Tsorng-Juu Liang, "Analysis and implementation of a novel bidirectional DC-DC converter." IEEE Transactions on Industrial Electronics,59(1), pp.422-434,2012

[4]K.Shreelekha and S.Arulmozhi, "Multiport isolated bidirectional DC-DC converter interfacing battery and supercapacitor for hybrid energy storage application." in International Conference on Electrical, Electronics, and Optimization Techniques (ICEEOT), 2016 IEEE (pp. 2763- 2768).

[5]Abdelsalam A. Ahmed, Mohamed G. Mousa and Young I1 Lee, "Regenerative braking control of IM with battery/ultracapacitor hybrid ESS in electric vehicles." in nineteenth International Middle East Power Systems Conference (MEPCON), Menoufia University, Egypt, 2017 IEEE (pp. 320-325).

[6]Fan Zhang, Xu Zhang, Min Zhang, Abigail S. E. Edmonds, “ Literature review of electric vehicle technology and its applications." in 5th International Conf. on computer science and network technology (ICCSNT), 2016 IEEE (pp. $832-$ 837).

[7]Ahmed M. Omara and M. Sleptsov, "Bidirectional interleaved DC/DC converter for electric vehicle application." in IFOST: Mechatronics, Electrical Engineering and Power Electronics, 2016 IEEE (pp. 100-104).

[8]Zhen Zhang, and Kwok-Tong Chau, "Pulse-width-modulation-based electromagnetic interference mitigation of bidirectional grid connected converters for electric vehicles.” IEEE Transactions On Smart Grid,8(6), 2017,pp. 28032812.

[9]M. H. Rashid, "Power Electronics: Circuits, Devices and Applications." 2004,3 ${ }^{\text {rd }}$ Edition. 